\author{
Pathophysiology \\ Haemostasis \\ and Thrombosis
}

\title{
Haemostatic Cardiovascular Risk Factors: Differential Effects of Red Wine and Diet on Healthy Young Population
}

\author{
Diego Mezzano, Federico Leighton
}

Department of Hematology-Oncology,

School of Medicine, and Department of Cell and Molecular Biology, Faculty of Biological Sciences, P. Catholic University of Chile.

\section{Key Words}

Cardiovascular risk factors - Coagulation factors .

Mediterranean diet $\cdot$ Wine $\cdot$ Platelet function

\begin{abstract}
Two groups (21 healthy young male each) received either Mediterranean-type diet (MD) or high-fat diet (HFD) during 90 days. Between days 30-60, both diets were supplemented with $240 \mathrm{ml} /$ day of red wine. MD alone was associated with: lower plasma fibrinogen ( $p$ $=0.03)$, factor VIIC $(p=0.034)$ and factor VIIIc $(p=0.0057)$; higher levels of protein $S(p=0.013)$; longer BT $(p=0.017)$; and marginal increases in platelet serotonin aggregation and secretion after stimulation with epinephrine. Red wine supplementation in both diets, resulted in lower plasma fibrinogen $(p=0.001)$ and factor VIIc $(p=0.05)$, and in increased $t-$ PA ( $p=0.01)$ and PAI-1 $(p=0.0003)$. The effects of wine on antithrombin III $(p=0.01)$ were divergent, with a decrease in the HFD group and an increase in the MD group. No effects of diet or wine were detected in plasma proteins $\mathrm{C}$ and S, BT or VWF:Ag. Wine supplementation also resulted in a significant increase in ex vivo platelet aggregation and secretion after stimulation with collagen ( 1 and $2 \mathrm{~g} / \mathrm{ml}, \mathrm{p}<=0.01$ ).

MD and moderate consumption of red wine have com-
\end{abstract}

plementary, mostly beneficial effects on haemostatic $\mathrm{CV}$ risk factors. The longer BT in individuals on MD, independently of red wine, would denote less interaction of platelets with the vascular wall, which would be beneficial from the point of view of $\mathrm{CV}$ risk. However, the increased platelet aggregation/secretion after wine intake, possibly a "rebound" phenomenon, would be a risk factor for thrombosis.

Copyright () 2004 S. Karger AG, Basel

\section{Introduction}

Some dietary habits and light-to-moderate alcohol consumption provide cardiovascular (CV) protection. In fact, foods of animal origin are directly correlated with coronary heart disease mortality, whereas an inverse correlation was found for vegetable-food groups, fish and alcohol [1]. Populations consuming a Mediterranean diet (MD), including wine had the lowest mortality among the seven countries included in that study. The benefits of this diet can apparently be transferred to populations of other ethnic origins [2] and have also been reproduced in secondary prevention trials [3].

Alcoholic beverages, mostly wine, are a constitutive component of the MD, and wine itself appears to add an

\section{KARGER}

Fax +41613061234

E-Mail: karger@karger.ch

www.karger.com
(C) 2004 S. Karger AG, Basel

$1424-8832 / 04 / 0336-0472 \$ 21.0 / 0$

Accessible online at: www.krager.com/pht
Diego Mezzano, MD

Department of Hematology-Oncology

School of Medicine, P. Catholic University of Chile.

Marcoleta 345, P.O. Box 114-D

Santiago, Chile

Tel: +56 2354 3774; E-mail: dmezzano@med.puc.cl 
independent CV benefit to this diet [4]. However, wine drinking also has been related to the intake of healthier diets [5] and other advantageous lifestyle characteristics [6], to which CV benefits are attributed. The health benefits of phenolic acids and polyphenols contained in red wine may be indiscernible in populations consuming large amounts of fruits and vegetables, whereas these benefits could be distinctly apparent in populations with relatively low intakes of these kinds of foods [7]. In this regard, the proposal that wine is a major determinant of the benefits derived from MD and the French paradox [8] still needs demonstration.

Lower rates of CV disease and mortality in Southern Europe countries could be only partially explained by differences in fat intake or in blood lipid profiles [9]. The concentration of several haemostatic factors are currently considered predictors for coronary heart disease [10], and some of them are modifiable by diet and alcohol (including wine). [11-15]. Platelet-vascular wall interactions (primary haemostasis) play a key role in arterial thrombotic events. This explains the increasing use of platelet inhibitors to prevent or treat these conditions. In this context, some of the beneficial effects of MD and wine consumption could be mediated by a reduction in platelet reactivity. Several studies report that diets enriched with fish, alpha linolenic acid and some spices, as well as the intake of moderate amounts of ethanol or nonalcoholic components of wine, for two or more weeks, are associated with a decrease in ex vivo platelet function [16-24].

In this symposium, we summarize the results of an intervention study which have been recently published [25,26]. The objectives of the studies were two-fold: 1) to compare the effects of two alcohol-free diets, a Mediterranean-type and a high-fat Western-type diet (HFD) on plasma concentration of emergent haemostatic cardiovascular risk factors (HCVRF) and on variables of primary haemostasis (bleeding time, plasma von Willebrand factor and platelet aggregation/ secretion); and 2) to test if red wine supplementation, independent of diet, modifies these variables.

\section{Methods}

In a controlled prospective intervention study, two groups, each of 21 healthy male university students (22 \pm 3.4 years), received either MD or HFD during 90 days. Between days 30-60, both diets were supplemented with $240 \mathrm{ml} /$ day of red wine (Figure 1). Baseline (T0) and T30, T60 and T90-day samples were drawn. Both diets were designed to provide the same caloric intake, with a daily average of $2565 \mathrm{kcal} /$ day. Proteins supplied $17.6 \%$ of total calories for each diet. Fats supplied $27.3 \%$ and $39.9 \%$ of calories for MD and HFD, respectively. Mean contents of saturated, monounsaturated, polyunsaturated and omega-3

Haemostatic Cardiovascular Risk Factors

\begin{tabular}{|l|l|c|c|}
\hline GROUP 1 & MEDITERRANEAN DIET & $\begin{array}{c}\text { MEDITERRANEAN DIET } \\
+ \\
\text { RED WINE }\end{array}$ & MEDITERRANEAN DIET \\
\cline { 2 - 4 } & 30 Days & 30 Days & 30 Days \\
\hline GROUP 2 & $\begin{array}{c}\text { HIGH FAT DIET } \\
+ \\
\text { RED WINE }\end{array}$ & HIGH FAT DIET \\
\hline
\end{tabular}

Fig. 1. Diagram of the diet and wine intervention design.

fatty acids provided by MD and HFD were 22.7 vs. 35.8 g/day, 37.9 vs. 35.5 g/day, 9.6 vs. 32.0 g/day, and 1.64 vs. $0.96 \mathrm{~g} /$ day, respectively. Individuals on MD consumed an average of $32 \mathrm{~mL} /$ day of olive oil. Fruit and vegetable consumption were, on the average, 675 g/day in MD and 246 g/day in HFD. White meat, fish and legumes were the main source of proteins in MD, whereas HFD was rich in red meat and low in fish. Bleeding time was measured before (day 30) and after (day 60) wine supplementation. A diagram showing the design of the intervention study is shown in Figure 1.

We measured procoagulant HCVRF (plasma fibrinogen, factors VIIc and VIIIc), anticoagulant proteins (antithrombin III, proteins $\mathrm{C}$ and S), tissue-type plasminogen activator (t-PA), plasminogen activator inhibitor (PAI-1) and variables of platelet-vessel wall interaction: template bleeding time (BT, an overall in vivo test assessing this interaction), plasma von Willebrand factor, and platelet aggregation and 14C-5-HT secretion after stimulation with various agonists.

\section{Results}

The compliance with diets was assessed by measuring several variables which distinguish the intake of MD and HFD after 30 days of either one or the other diet. As expected, individuals on MD had significantly higher levels of plasma beta-carotene (0.49 0.19 vs $0.23 \quad 0.14 \mathrm{~mol} / \mathrm{L}$; p < 0.0001), ascorbate (55.9 11.2 vs $29.7 \quad 8.9 \mathrm{~mol} / \mathrm{L} ; \mathrm{p}<$ 0.0001 ), folate (14.2 4.3 vs $10.52 .6 \mathrm{nmol} / \mathrm{L} ; \mathrm{p}=0.0019)$ and eicosapentaenoic acid in the plasma lipid fraction (1.5\% 0.7 vs $0.85 \% 0.3 ; \mathrm{p}=0.001$ ), than those on HFD. However, dietary and wine interventions did not result in significant changes, at any time point, in total plasma cholesterol, nor in HDL and LDL in either study group (results not shown).

No significant differences were observed in plasma concentration of HCVRF at baseline (T0) between groups on MD and HFD. The effects of diet alone were tested comparing values of each variable for MD and HFD at T0 and T30, a period without wine supplementation (Figure 2). 

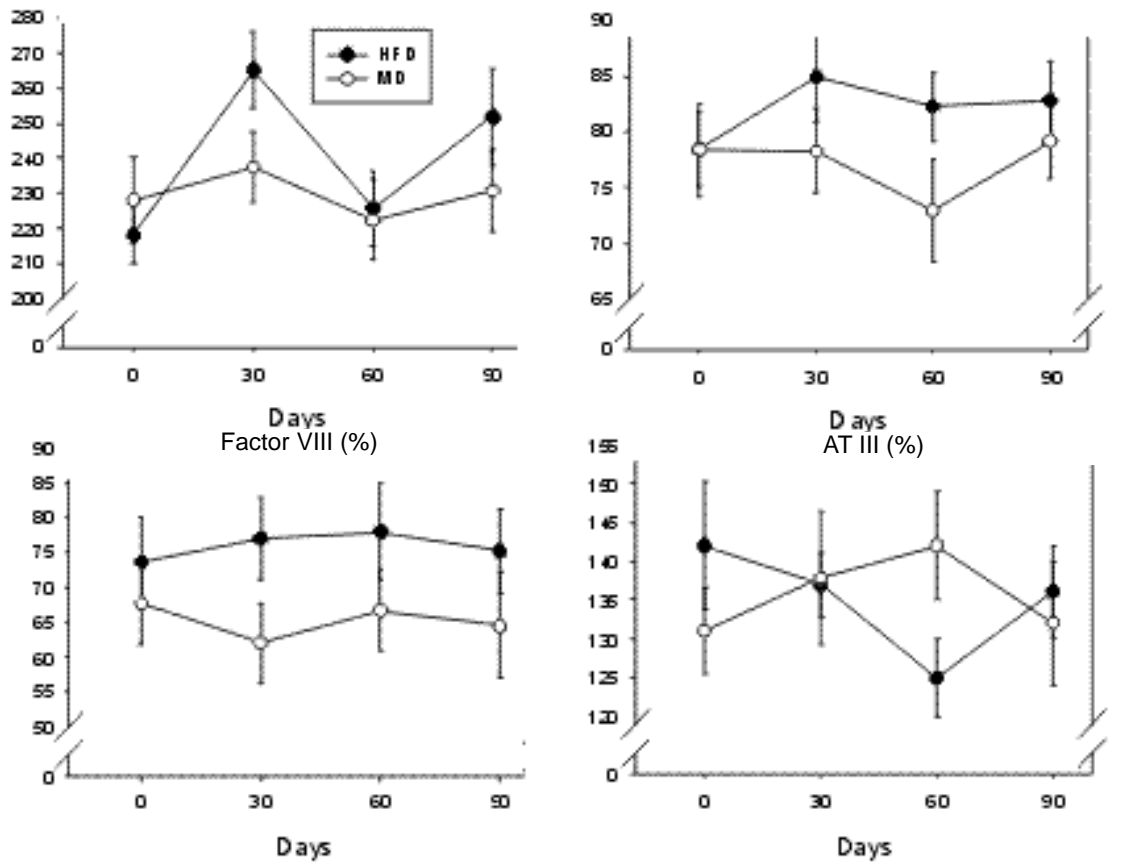

Fig. 2. Comparative effect of Mediterranean diet (MD) and high-fat diet (HFD), and effect of red wine on plasma fibrinogen, factor VIIc, factor VIIIc and antithrombin III. Volunteers received red wine from day 30 through 60. At T30 there was a diet-related difference in fibrinogen ( $p=0.03$ ), factor VIIc $(p=0.034)$ and factor VIIIc ( $p=0.0057)$ levels, with lower values in individuals on MD. For the natural anticoagulant antithrombin III, the inverse effect observed with each diet abolished the difference at T0. Wine intake was associated with decreases in plasma fibrinogen $(p=0.0005)$ and in factor VIIc $(p$ $=0.05)$. The mean change in AT III Ag after wine consumption differed significantly in volunteers on HFD when compared with those on MD ( $p=0.01)$. (With permission of Biol Res 2004; 37:217).

Volunteers on HFD at T30 had 22\% increase in pro-coagulants fibrinogen, $9 \%$ increase in factor VIIc, and $4 \%$ in factor VIIIc, and decreases in natural anticoagulants antithrombin III (3\%), protein C (11\%) and protein S (6\%) and of 20\% in plasminogen activator inhibitor-1 (data for antithrombin III is also shown in Figure 2). At the same time, individuals on MD had marginal increases in fibrinogen (4\%), antithrombin III (5\%), protein C (3\%), protein S (2.7\%), and decreases in factor VIIIc (9\%), and plasminogen activator inhibitor-1 (21\%, Figure 3). After adjusting by baseline values, MD was associated with lower plasma procoagulants fibrinogen ( $p=0.03)$, factor VIIc $(p=0.034)$ and factor VIIIc $(p=0.0057)$ and with higher levels of the anticoagulant protein $S(p=0.013)$. Taken together, all these changes can be interpreted as indicating a cardiovascular protection of MD against thrombin generation and fibrin clot deposition in the circulation.
The effect of red wine supplementation was tested comparing values obtained after 30 days with wine (T60) in both diets, with values at T30 T90 2. Furthermore, to control for a longer than expected wine effect, comparisons at T60 and T30 were performed. As shown in the same Figures, wine intake resulted in a diet-independent decrease in plasma fibrinogen ( $p=0.001)$ and factor VIIc $(p=0.05)$, and in increase in tissue plasminogen activator antigen $(\mathrm{p}=0.01)$ and plasminogen activator inhibitor- 1 antigen $(p=0.0003)$. Wine consumption was also associated with significantly $(\mathrm{p}=0.01)$ divergent effects on antithrombin III: it decreased by $10 \%$ in individuals on HFD but increased slightly in those on MD. These findings show that red wine intake has an overall potentiating effect of MD, by decreasing the procoagulant potential of plasma and increasing its anticoagulant properties. In this regard, the wine-induced increase in PAI-1 is paradoxic, since its net effect would be a decrease in the capacity of plasma to lyse clots. 

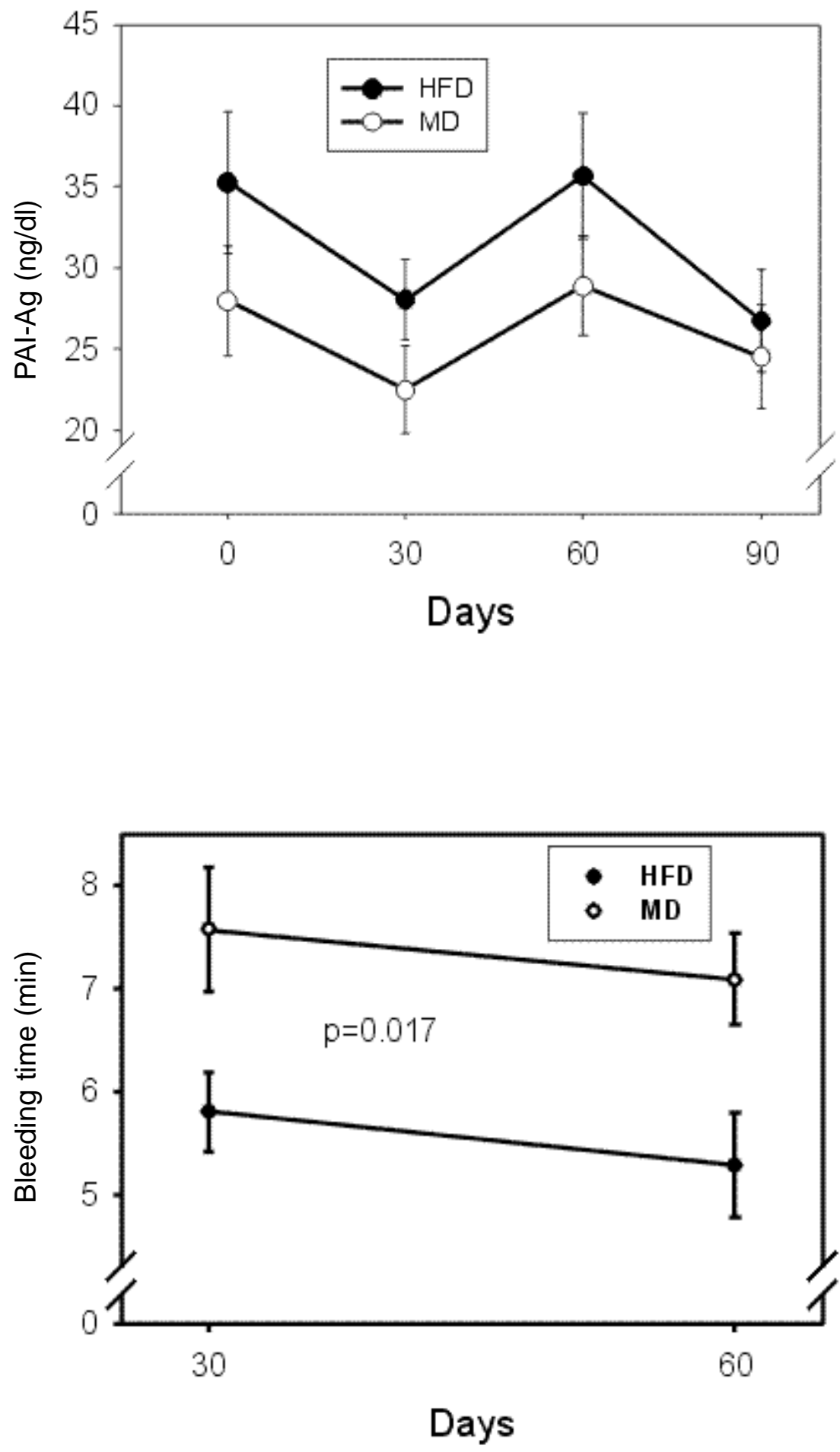

Fig. 3. Comparative effect of Mediterranean diet (MD) and high-fat diet (HFD), and effect of red wine on plasma plasminogen activator inhibitor-1 antigen. Volunteers received red wine from day 30 through 60 . Wine intake was associated with increase in plasma PAI-1 Ag $(\mathrm{p}=0.0001)$. (With permission of Biol Res 2004; 37:217).

Fig. 4. Comparative effect of Mediterranean diet (MD) and high-fat diet (HFD) and the effect of red wine on bleeding time. Values were recorded after 1 month on each diet (day 30) and after 1 month of supplementation of both diets with red wine (day 60). "p" value reflects the difference in BT between diets. Red wine intake was not associated with significant changes in bleeding time. Bars represent mean SD. (With permission of Biol Res 2004; 37:217). 
With regard to variables related to platelet-vessel wall interaction, individuals on MD had longer BT than those on HFD (7.6 2.8 vs. $5.81 .7 \mathrm{~min} ; \mathrm{p}=0.017$ ) measured at T30 (Figure 4). BT did not change significantly after 1 month of wine supplementation (7.1 2.0 vs. $5.52 .0 \mathrm{~min}$, respectively). Bleeding time is an in vivo test which is altered in conditions of abnormal interactions of platelets with the vessel wall. Plasma concentration of von Willebrand factor (vWF:Ag) was not significantly different between diet groups at baseline and did not change significantly at 30, 60 or 90 days. VWF:Ag is a three-compartment (intraplatelet, circulating and subendothelium matrix) glycoprotein which mediates the interaction of platelets with the vascular wall, and whose increased concentration has been directly related with cardiovascular risk. MD intake was associated with an increase in platelet serotonin secretion ( $p=0.02)$ and aggregation $(p=0.07)$ after stimulation with epinephrine. Wine intake resulted in a marginal decrease in platelet 14C-5-HT secretion with 4 M ADP ( $p=0.07)$, whereas both platelet aggregation and secretion were consistently increased when using collagen as agonist ( $p$ 0.01). These results stand against the commonly accepted notion that red wine decreases the cardiovascular risk by inhibiting platelet function, appealing for additional explanations for the French paradox [8].

Given that inflammatory stimuli induce increase in some coagulation proteins, C-reactive protein was measured at all times in all volunteers to control for inflammatory changes within individuals and within groups. No significant baseline differences, nor changes induced by diet or wine in this inflammatory marker were observed (results not shown).

\section{Conclusions}

MD and moderate consumption of red wine have complementary, mostly beneficial effects on HCVRF. Our studies confirmed the overall health advantage of a MD (less total and saturated fats and red meat, but richer in monounsaturated fatty acids, white meat, fish, fruits and vegetables). It also revealed that the addition of a moderate amount of red wine further improves the haemostatic profile of this type of diet, as well as that of individuals with higher fat diets. The net effect of combining diet and red wine is a decrease in the procoagulant potential of plasma. However, a note of caution must be added, regarding a possible antifibrinolytic effect of wine, when it supplements the MD.

With respect to primary haemostasis, MD, independent of wine, was found associated with a longer BT. This finding denotes less interaction of platelets with the vascular wall, which could be beneficial from the point of view of cardiovascular (CV) risk. This effect is not explained by changes in the measured haemostatic determinants of BT (plasma vWF, ex vivo platelet function), and might be attributed to other as yet unknown vascular factors.

It is unlikely that abondance of fish or omega-3 fatty acids in the diet explains the observed effect [27,28], because fish intake in our MD group was lower than that used in previous specific intervention studies, and it did not result in significant changes in platelet aggregation/secretion. Nitric oxide (NO) and prostacyclin (PGI2) produced by endothelial cells reduce platelet-vessel wall interactions and both induce prolongation of BT [29-31]. In this context, it is possible that the modulation of NO on platelet-endothelium interactions could account for the longer BT presently observed for individuals on MD.

Notwithstanding, a significant increase in the aggregation and secretion of platelets exposed to low and high collagen concentrations was observed. This finding contests the widespread notion, summarised in recent reviews, that red wine inhibits platelet function [32,33]. In fact, the undisputed CV benefits of moderate red wine consumption parallels the wide consensus that wine effects are, at least in part, induced by inhibiting platelet reactivity. Studies assessing the effect of wine on platelets are highly heterogeneous and the inhibition observed with a single stimulus is often not reproduced with other agonists. Moreover, a distinct increase in ex vivo platelet function has been observed with some agonists in association with wine intake, and an additional increase in platelet reactivity, referred to as the rebound effect, has been noted after alcohol withdrawal [34]. In this regard, our finding of increased platelet aggregation/secretion with collagen closely resembles a rebound effect, given that it arises several hours after the last drink, with no alcohol remaining in the blood. This situation best reflects the physiological status of a moderate wine drinker.

The potential antithrombotic advantage of consuming a Mediterranean-type of diet associated with moderate amount of red wine has not a straightforward biological explanation. Even though a balanced ratio of omega6/omega-3 essential fatty acids and abundance of antioxidant compounds may have a mild anti-inflammatory effect [35], the lack of significant differences in plasma levels of CRP protein between both diets does not support this interpretation. The possibility that a decreased oxidative injury derived from MD and red wine consumption [36] modulates the coagulation system deserves a systematic evaluation.

In our studies, we tested the effect of red wine because it constitutes the major alcoholic beverage consumed with MD. As previously discussed, some of the effects observed in our study have also been attributed to ethanol contained in other alcoholic beverages. It remains to be established the relative contributions of alcohol and other constituents of red wine, such as polyphenols, in the improved CV risk factor profile associated to moderate red wine intake. 


\section{References}

1 Menotti A, Kromhout D, Blackburn H, Fidanza F, Buzina R, Nissinen A. Food intake patterns and 25-year mortality from coronary heart disease: cross-cultural correlations in the Seven Countries Study. The Seven Countries Study Research Group. Eur J Epidemiol 1999;15:507-515.

$>2$ Kouris-Blazos A, Gnardellis C, Wahlqvist ML, Trichopoulos D, Lukito W, Trichopoulou A. Are the advantages of the Mediterranean diet transferable to other populations? A cohort study in Melbourne, Australia. Br J Nutr 1999;82:57-61.

-3 de Lorgeril M, Salen P, Martin JL, Monjaud I, Delaye J, Mamelle N. Mediterranean diet, traditional risk factors, and the rate of cardiovascular complications after myocardial infarction: final report of the Lyon Diet Heart Study. Circulation 1999;99:779-785.

-4 Gronbak M, Becker U, Hohansen D, Gottschau A, Schnohr P, Hein HO, Jensen G, Sorensen TIA. Type of alcohol consumed and mortality from all causes, coronary heart disease, and cancer. Ann Int Med 2000;133:411-419.

$\checkmark 5$ Tjonneland A, Gronbak M, Stripp C, Overvad $\mathrm{K}$. Wine intake and diet in a random sample of 48,763 Danish men and women. Am J Clin Nutr 1999;69:49-54.

-6 Wannamethee SG, Shaper AG. Type of alcoholic drink and risk of major coronary heart disease events and all-cause mortality. Am J Public Health 1999;89:685-690.

7 de Lorgeril M, Salen P. Wine ethanol, platelets, and mediterranean diet. Lancet 1999;353:1067.

-8 Renaud S, de Lorgeril M. Wine, alcohol, platelets, and the French paradox for coronary heart disease. Lancet 1992;339:15231526.

-9 Langer RD, Criqui MH, Reed DM. Lipoproteins and blood pressure as biological pathways for effect of moderate alcohol consumption on coronary heart disease. Circulation1992;85:910-915.

10 Ridker PM. Fibrinolytic and inflammatory markers for arterial occlusion: the evolving epidemiology of thrombosis and hemostasis. Thromb Haemost 1997;78:53-59.

11 Weststrate JA, van het Hof $\mathrm{KH}$, van den Berg H, Velthuis-te-Wierik EJ, de Graaf C, Zimmermanns NJ, Westerterp KR, Westerterp-Plantenga MS, Verboeket-van de Venne WP. A comparison of the effect of free access to reduced fat products or their full fat equivalents on food intake, body weight, blood lipids and fat-soluble antioxidants levels and haemostasis variables. Eur J Clin Nutr 1998;52:389-395.
12 Roche HM, Zampelas A, Knapper JM, Webb D, Brooks C, Jackson KG, Wright JW, Gould BJ, Kafatos A, Gibney MJ, Williams CM. Effect of long-term olive oil dietary intervention on postprandial triacylglycerol and factor VII metabolism. Am J Clin Nutr 1998;68:552-560.

13 Temme EH, Mensink RP, Hornstra G Effects of diets enriched in lauric, palmitic or oleic acids on blood coagulation and fibrinolysis. Thromb Haemost 1999;81:259263.

14 Mezzano D, Munoz X, Martínez C, Cuevas A, Panes O, Aranda E, Guasch V, Strobel P, Munoz B, Rodríguez S, Pereira J, Leighton F. Vegetarians and cardiovascular risk factors: haemostasis, inflammatory markers and plasma homocysteine. Thromb Haemost 1999;81:913-917.

15 Rimm EB, Williams P, Fosher K, Criqui M, Stampfer MJ. Moderate alcohol intake and lower risk of coronary heart disease: metaanalysis of effects on lipids and haemostatic factors. BMJ 1999;319:1523-1528.

16 Vognild E, Elvevoll EO, Brox J, Olsen RL, Barstad H, Aursand M, Osterud B. Effects of dietary marine oils and olive oil on fatty acid composition, platelet membrane fluidity, platelet responses, and serum lipids in healthy humans. Lipids 1998;33:427-436.

17 Allman MA, Pena MM, Pang D. Supplementation with flaxseed oil versus sunflowerseed oil in healthy young men consuming a low fat diet: effects on platelet composition and function. Eur J Clin Nutr 1995:49:169-178.

18 Janssen K, Mensink RP, Cox FJ, Harryvan JL, Hovenier R, Hollman PC, Katan MB Effects of the flavonoids quercetin and apigenin on hemostasis in healthy volunteers: results from an in vitro and a dietary supplement study. Am J Clin Nutr 1998; 67:255-262.

19 Ackerman RT, Mulrow CD, Ramirez G, Gardner CD, Morbidoni L, Lawrence VA Garlic shows promise for improving some $\mathrm{CV}$ risk factors. Arch Intern Med 2001;161:813-824.

20 Srivastava KC, Bordia A, Berma SK. Curcumin, a major component of food spice turmeric (Curcuma longa) inhibits aggregation and alters eicosanoid metabolism in human blood platelets. Prostaglandins Leukot Essent Fatty Acids 1995;52:223227.

21 Pikkar NA, Wedel M, van der Beek EJ, van Dokkum W, Kempen HJ, Kluft C, Ockhuizen T, Hermus RJ. Effects of moderate alcohol consumption on platelet aggregation, fibrinolysis, and blood lipids. Metabolism 1987;36:538-543.
-22 Pellegrini N, Pareti FI, Stabile F, Brusamolino A, Simonetti P. Effect of moderate consumption of red wine on platelet aggregation and haemostatic variables in healthy volunteers. Eur J Clin Nutr 1996; 50:209-213.

-23 Pace-Asciak CR, Rounova O, Hahn SE, Diamandis EP, Goldberg DM. Wines and grape juices as modulators of platelet aggregation in healthy human subjects. Clin Chim Acta 1996;246:163-182.

-24 Freedman JE, Parker C III, Li L, Perlman JA, Frei B, Ivanov V, Deak LR, Iafrati MD, Folts JD. Select flavonoids and whole juice from purple grapes inhibit platelet function and enhance nitric oxide release. Circulation 2001;103:2792-2798.

25 Mezzano D, Leighton F, Martínez C, Marshall G, Cuevas A, Castillo O, Panes O, Munoz B, Pérez DD, Mizón C, Rozowski J, San Martín A, Pereira J. Complementary effects of Mediterranean diet and moderate red wine intake on haemostatic cardiovascular risk factors. Eur J Clin Nutr 2001; 55:444-451.

-26 Mezzano D, Leighton F, Strobel P, Martínez C, Marshall G, Cuevas A, Castillo O, Panes O, Munoz B, Rozowski J, Pereira. Mediterranean diet, but not red wine, is associated with beneficial changes on primary haemostasis. Eur J Clin Nutr 2003;57:439-446.

-27 Dyerberg J, Bang HO. Haemostatic function and platelet polyunsaturated fatty acids in Eskimos. Lancet 1979;2:433-435.

28 Goodnight SH Jr, Harris WS, Connor WE. The effects of dietary omega 3 fatty acids on platelet composition and function in man: a prospective, controlled study. Blood 1981; 58:880-885.

29 Simon DI, Stamler JS, Loh E, Loscalzo J, Francis SA, Creager MA. Effects of nitric oxide synthase inhibition on bleeding time in humans. J Cardiovasc Pharmacol 1995; 26:339-342.

-30 Ubatuba FB, Moncada S, Vane JR. The effect of prostacyclin (PGT2) on platelet behaviour. Thrombus formation in vivo and bleeding time. Thromb Haemost 1979; 23:425-435.

31 Gerrard JM, Duta E, Nosek-Cenkowska B, Singhroy S, Cheang M, Kobrinsky NL. A role for prostacyclin in bruising symptomatology. Pediatrics 1992;90:33-36.

$\checkmark 32$ Wollin SD, Jones PJH. Alcohol, red wine and cardiovascular disease. J Nutr 2001; 131:1401-1404.

-33 Booyse FM, Parks DA. Moderate wine and alcohol consumption: beneficial effects on cardiovascular disease. Thromb Haemost 2001; 86:517-528. 
34 Renaud SC, Ruf J-C. Effects of alcohol on platelet functions. Clin Chim Acta 1996; 246:77-89.
35 de Lorgeril M, Salen P. Modified Cretan Mediterranean diet in the prevention of coronary heart disease and cancer. In Simopoulos AP, Visioli F (eds): Mediterranean Diets, Basel, Karger, 2000, pp 1-23.
36 Visioli F. Antioxidants in Mediterranean diets. In Simopoulos AP, Visioli F (eds): Mediterranean Diets, Basel, Karger, 2000, pp 43-55. 